\title{
REFLEXÕES SOBRE A INFLUÊNCIA DA TECNOLOGIA NA VIDA ATUAL A PARTIR DO LIVRO A OBRA DE ARTE NA ERA DA SUA REPRODUTIVIDADE TÉCNICA DE WALTER BENJAMIM
}

\author{
Enock da Silva Peixoto
}

\begin{abstract}
RESUMO
O objetivo deste texto é abordar a partir do ensaio: $A$ obra de arte na era da sua reprodutibilidade técnica de Walter Benjamim, as transformações ocorridas nos diversos meios de reprodução da obra de arte no Ocidente e associar esta reflexão a presença das novas tecnologias na vida contemporânea. As alterações na relação humana com a arte, desde a Antiguidade, têm trazido decorrências objetivas sobre os comportamentos. Mas na era Moderna, com a ascensão do cinema e da fotografia, iniciou a influência mais violenta e avassaladora de todos os tempos. Emergiram efeitos na compreensão da própria perspectiva estética do mundo, no campo da política e, sobretudo, no modo como ressignificamos a realidade. O nosso estudo sobre o tema é ainda insipiente e não pretendemos estabelecer um debate estrito entre a obra de arte e os meios de comunicação atuais, mas conjuntamente e a partir de Benjamim, objetivamos pensar sobre os efeitos dos vigentes meios de comunicação frente a nossa percepção de nós mesmos e do mundo.
\end{abstract}

Palavras chave: obra de arte, tecnologia, percepção, comportamento, contemporaneidade.

\section{REFLECTIONS ABOUT THE INFLUENCE OF TECHNOLOGY IN CURRENT LIFE BASED IN TE BOOK THE WORK OF ART IN THE AGE OF MECHANICAL REPRODUCTION BY WALTER BENJAMIN}

\begin{abstract}
The purpose of this paper is to address from the test: The work of art in the age of its technical reproducibility of Walter Benjamin, the changes occurred in the various means of reproduction of the artwork in the West and associate this reflection the presence of new technologies in life contemporary. Changes in the human relation to art, from ancient times, have brought objective derivations on behavior. But in the modern era, with the rise of cinema and photography, he began the most violent and overwhelming influence of all time. Effects emerged in the understanding of one's aesthetic perspective of the world, in politics, and


especially in the way we give another meaning to reality. Our study on the subject is still incipient and do not intend to establish a strict debate between the artwork and the current media but jointly and from Benjamin, we aim to think about the effects of the current front media our perception of ourselves and the world.

Keywords: work of art, technology, perception, behavior, contemporaneity.

\section{Introdução}

O ensaio de Walter Benjamin em questão passou por várias redações, sendo que uma delas foi traduzida para o francês e as outras três foram versões em alemão. A edição francesa foi à única publicada em vida na Revista de Pesquisas Sociais em 1936. Benjamin trabalhou em torno destes textos entre os anos de 1935 e 1939 (SCHOTTKER, 2012). Em 1939, estabelece várias mudanças na redação e esta foi a última revisão realizada pelo filósofo. Ela não foi publicada em vida, mas postumamente.

O texto está dividido em duas partes básicas ${ }^{1}$, a primeira está incluída entre os capítulos I e VII, além de um preâmbulo. Nessas o filósofo faz um panorama do processo de reprodução na arte desde a Antiguidade até a Modernidade. Na segunda parte, o tema central é o cinema e a sua significativa presença na reprodução estética e como este fato interferiu, segundo Benjamim, na forma como o ser humano percebe o existir. Esta parte termina no capítulo XV, acrescida de um epílogo.

O propósito de escrever sobre este ensaio emerge de um estudo mais sistemático, mas ainda inicial, sobre as obras de Walter Benjamim. As motivações que nos impulsionaram a revisitar o texto e ousar dialogar com as temáticas que suscita, não foram somente as preocupações que motivaram o filósofo em questão a escrevê-la, mas, o nosso próprio tempo, as nossas vivencias contemporâneas e a maneira avassaladora como as novas

\footnotetext{
${ }^{1}$ Cf. Ibidem.
} 
tecnologias (Idem) atingem a compreensão que criamos sobre o mundo. $\mathrm{Na}$ verdade, nem absorvemos ainda a clareza sobre a extensão desta sobre nós!

Benjamim analisou as mudanças sociais, comportamentais e psicológicas da reprodutividade técnica causada principalmente pelo cinema e pela fotografia e como elas incidiram sobre os seres humanos, destacando, entre outros aspectos, a mudança de concepção de mundo advindas dessa relação. Queremos utilizar esta singular análise do filósofo para estabelecermos um paralelo, mesmo que preliminar, com a incidência das novas tecnologias na realidade atual e de que modo estas tem transformado ou atuado sobre nossas condutas e quais são algumas das consequências positivas e negativas neste processo. Sabemos de antemão que autores relevantes têm pensado sobre os efeitos da tecnologia na vida contemporânea, porém, pelo menos neste momento, não queremos fazer esta abordagem com estudos mais atuais e específicos voltados para o tema. Cientes de que a preocupação de Benjamim foi com a arte e a relação desta com a vida, e que a convivência contemporânea com a tecnologia não é necessariamente estética mais, sobretudo utilitária e instrumental, atentaremos principalmente para a influência na visão de mundo que ela pode nos proporcionar ou impor.

O nosso texto partirá de dois itinerários, primeiro, retomarei os principais pontos da obra fazendo uma explanação sobre o mesmo, visando estabelecer uma visão geral sobre os seus aspectos mais basilares. Em seguida, retomaremos as reflexões de Benjamim sobre a aura, sobre o inconsciente óptico e sobre a perspectiva política do livro. A partir destes pontos, analisaremos a nossa familiaridade contemporânea com o universo tecnológico, refletindo sobre alguns dos seus efeitos em nós e sobre a necessidade e urgência de problematizarmos insistentemente a conexão ser humano-tecnologia.

\section{A obra de arte na era da sua reprodutividade técnica ${ }^{2}$}

\footnotetext{
${ }^{2}$ Utilizaremos como fonte de análise do ensaio benjaminiano em estudo, a versão em língua portuguesa: BENJAMIN, Walter. A obra de arte na era da sua reprodutividade técnica. In: 
Walter Benjamin inicia o ensaio fazendo referência ao marxismo, dizendo que quando Marx empreendeu a análise do modo de produção capitalista, esta teve característica de prognóstico, como um modo de antever o que 0 futuro nos reservaria. Sustenta que como as mudanças na superestrutura são mais lentas que na infraestrutura, foi necessário meio século para que elas repercutissem na cultura. Para o filósofo era possível fazer alguns prognósticos ao analisar o desenvolvimento das artes nas condições de produção contemporâneas a ele. Benjamin cita ainda o fascismo que levantara uma série de conceitos consagrados como criatividade, genialidade, validade eterna, mistério, que deveriam ser substituídos por novos conceitos introduzidos pela teoria da arte e estes serem "úteis à formulação de exigências revolucionárias" (BENJAMIN, 2012). A referência ao marxismo e ao fascismo, logo na introdução, demonstra claramente a intenção política do texto, ou seja, entre outras questões, parece evidente que Benjamin quis abordar a arte como um instrumento de transformação social.

O filósofo alemão prossegue afirmando que sempre ocorreu reprodução das obras de arte. Na Antiguidade os gregos conheciam a fundição e a cunhagem; na Idade Média surgiu a gravura em água forte; no Início da era Moderna, a xilogravura, a gravura em metal e a imprensa. No final do século XIX surgiu a litografia que tornou possível trazer ao mercado todos os dias criações novas. No final do século XIX, a litografia foi substituída pela fotografia e pela primeira vez a mão foi dispensada nas práticas artísticas. "O olho" se tornou extremamente rápido no processo de reprodução de imagens e surgiu ainda no final do século antes citado, a reprodução do som. Ressaltemos que o cinema, foco principal do ensaio, surgiu também no final do século XIX.

Em seguida, a abordagem é sobre a originalidade da obra de arte. Acentua-se que mesmo na reprodução mais perfeita falta o caráter único da obra de arte. A sua autenticidade se encontra no aqui e agora original, algo que

Benjamim e a obra de arte: técnica, imagem, percepção. Tradução de Marijane Lisboa e Vera Ribeiro; org. Tadeu Capistrano. Rio de Janeiro: Contraponto, 2012. 
se perdeu com a reprodução técnica. Mesmo que o conteúdo da arte seja mantido, perde-se o seu aqui e agora, ela perde a sua aura. A existência única foi substituída pela serial. Tal processo está em consonância com os atuais (da época de Benjamin) movimentos de massa e o cinema foi o seu poderoso agente. Vale ressaltar que estávamos sobre a égide do modelo social e de trabalho inaugurado pela Revolução Industrial no qual a reprodução em série prevalecia. Esse é um dos panos de fundo da crítica de Benjamim e a arte não fugiu a tal invólucro.

O texto enfoca que a forma de percepção muda nas coletividades humanas no decorrer da história. É possível, por isso, apontar as causas sociais da perda da aura. Para melhor compreender o conceito de aura, o filósofo ilustra definindo-a como "a aparição única de algo distante, por mais próxima que esteja" (BENJAMIN, 2012, 16). Ao contemplarmos uma cadeia de montanhas, uma ramagem, podemos sentir as suas auras. Esta descrição ajuda a entender, segundo o filósofo, o atual declínio da aura e ele aponta duas circunstâncias que estão associadas à crescente influência das massas na vida atual: aproximar as coisas espacial e humanamente e superar o caráter único das coisas, graças a sua reprodução.

Benjamin escreve que a unidade da obra de arte é igual a sua inserção na tradição, que é algo vivo e mutável. Tanto na interpretação positiva dos gregos sobre a estátua de Vênus que era cultual, como na negativa dos medievais que a viam como um ídolo maligno, a aura dessa deusa era mostrada. As primeiras obras de arte serviram a ritos mágicos e depois religiosos, neste contexto, era fundamental que a obra de arte não se desprendesse de sua função ritual. O seu valor único tem valor no ritual onde ela se originou. Com a fotografia, o primeiro modo revolucionário de reprodução, pela primeira vez a arte se emancipa do ritual. Como o critério de autenticidade não se aplica mais a produção artística, a função social da arte sofreu grande transformação e o seu fundamento passa a ser a práxis política, não o ritual. A obra de arte, continua Benjamim, pode ser recepcionada de modos muito distintos, eles oscilam entre o seu valor de culto e o seu valor de 
exposição. Começaram com o seu valor de culto e à medida que se emanciparam, cresceu o seu valor de exposição. Os diversos modos de reprodução favoreceram este processo de distanciamento da magia passando mais tarde a ser reconhecido como arte.

A fotografia, com o seu valor de exposição, expulsou o valor de culto. Benjamin cita $\operatorname{Atget}^{3}$ que evidenciara o valor de exposição da fotografia ao retirar as pessoas das fotos. Ele fotografou as ruas vazias de Paris como se fossem uma cena de crime, e assim, testemunham um novo processo histórico com significado político oculto. A recepção não é mais comprometida como ocorreu com as revistas ilustradas que precisavam de legenda, e nos filmes com suas sequências de imagens; o espectador precisava buscar um caminho determinado.

O capítulo sete está no meio do ensaio e marca o início da segunda parte. Conforme Detlev Schottker, há nestes capítulos da metade do ensaio uma mudança no plano argumentativo. Isto ocorre de fato, pois as discussões históricas sobre a reprodução da arte darão lugar às questões contemporâneas, tendo o cinema como foco. Benjamin inicia afirmando que parece confusa e equivocada a discussão do século XIX sobre a pintura e a fotografia, polêmica que expressou uma revolução mundial e nenhum dos dois grupos teve consciência disso. Gastou-se muito tempo debatendo se a fotografia era arte, sem discutir como ela modifica a própria natureza da arte. $\mathrm{O}$ filósofo cita alguns teóricos do cinema de sua época que cometeram o mesmo erro, tentando introduzir a força elementos de culto ao cinema, Alexandre Arnoux ${ }^{4}$, por exemplo, comparara o filme a uma prece.

O filósofo distingue como é a representação no teatro e no cinema, procurando evidenciar características do cinema e a sua percepção. No teatro o ator exibe pessoalmente sua arte ao público, no cinema o seu desempenho é

\footnotetext{
${ }^{3}$ Eugène Atget nasceu em Paris no século passado e viveu entre 1857 a 1927. É considerado um dos mais revolucionários fotógrafos da História. Foi o pioneiro ao desviar o foco da fotografia para fora do ser humano.

${ }^{4}$ Alexandre Arnoux (1884-1973) foi um dramaturgo e romancista francês. Entre os seus trabalhos mais significativos ele escreveu diversas narrações e poemas marcados pela experiência da guerra.
} 
mediado pela máquina. Daí decorreu duas consequências: a máquina não é obrigada a respeitar inteiramente a encenação do ator, e ainda, a montagem final resultará da sequência do material resumido. Diversos testes ópticos submetem o desempenho. A segunda é que 0 ator não atua conforme as reações do público, ele não atua para o público, como no teatro, essa empatia ocorre por intermédio da máquina.

Benjamim distinguiu teatro e cinema para demonstrar as mutações referentes à imagem ocorridas no mundo moderno. Ele cita o romance de Pirandello ${ }^{5}$ onde esse aponta 0 efeito da técnica de filmagem na representação. Pirandello fora o primeiro a observar a transformação do interprete pela experiência do teste. O que importa é o que este significa para a máquina. $O$ ator se sente exilado, não só no palco, mas de si mesmo. $O$ público é substituído pela máquina e desaparece a aura que envolve 0 interprete e o personagem. $O$ teatro é o gênero artístico que se opõe de modo mais radical, à obra de arte por meio da reprodução técnica. A atuação do artista do cinema é composta por sequências isoladas e por isso, "a arte escapou do reino das belas aparências" (BENJAMIN, 2012, 24).

No capítulo X Pirandello é novamente citado, pois ele teria observado a estranheza do interprete diante da máquina como semelhante a do indivíduo diante do espelho. $\mathrm{O}$ artista frente à câmera sabe de sua relação íntima com o público de consumidores, sua proximidade com esse mercado se assemelha aos artigos manufaturados de uma fábrica. O culto ao estrelato, porém, mantém aquela magia perdida pelo caráter mercantil. Benjamin não nega que 0 cinema pudesse ir além dessa crítica às concepções tradicionais de arte, vindo a ser revolucionária, mas isto não estava ocorrendo em sua época.

Em seguida, o ensaio volta-se novamente para a análise da questão estética, considerando as imagens do cinema. Afirma-se que a realização de um filme oferece um espetáculo antes inimaginável. O conjunto das atividades que abarca não pode ser observado por um único ângulo, como ocorrem com

\footnotetext{
${ }^{5}$ O dramaturgo italiano Luigi Pirandello viveu entre 1867 a 1936. Foi um renovador do teatro e ganhou em 1934 o Nobel de Literatura.
} 
as máquinas de filmagem, os objetos de iluminação e outros aparelhos. A localização do palco no teatro nos faz perceber o ilusionismo da encenação, o que não ocorre com o cinema. Essa relação fica ainda mais destacada na pintura. Para evidenciar isto, Benjamin faz a analogia entre o mágico e o cirurgião. A magia mantém distancia entre ela e o paciente; o médico é direto, ele manipula os órgãos do paciente, embora mantenha uma distancia operacional, de homem para homem. O mágico está para o cirurgião como 0 cineasta para o pintor. O pintor observa à distancia uma realidade dada, 0 cineasta penetra no tecido do objeto. As imagens produzidas por ambos são distintas. A do pintor é total e a do cineasta é composta por vários fragmentos.

Walter Benjamim sustenta que o que caracteriza o cinema não é como o homem se representa diante da máquina, mas como ele representa o mundo graças a ela. Diz que a Psicologia experimental permitiu entender como a máquina funciona como teste. A Psicanálise trouxe outra perspectiva: há cinquenta anos os lapsos não eram considerados fenômenos importantes e após Sobre a Psicopatologia da vida cotidiana ${ }^{6}$ ocorreu uma valorização dos lapsos de memória. De modo semelhante, o cinema ampliou a nossa visão de mundo. A visão sobre o cotidiano é ampliada, como por exemplo, o foco em detalhes ocultos, a análise de ambientes comuns, a ampliação do espaço com primeiros planos, a ampliação do movimento com a câmera lenta. Abre-se pela primeira vez o nosso "inconsciente óptico", assim como a Psicanálise revelou o inconsciente pulsional. Inconsciente óptico, neste contexto benjaminiano, parece significar a ampliação da percepção que o homem moderno adquiriu, por influência do cinema.

O penúltimo capítulo, o quatorze, é iniciado afirmando-se que uma das tarefas da arte seria antecipar tempos futuros. O dadaísmo tentou obter os

${ }^{6}$ O austríaco, médico neurologista e criador da psicanálise Sigmund Freud (1856-1939), publicou em 1901 Sobre a Psicopatologia da Vida Cotidiana que é um dos marcos no estudo sobre o inconsciente humano. Uma das teses centrais é de que a nossa racionalidade não é capaz de explicar todos os fenômenos que envolvem a nossa existência. Fatos como lapsos, atos falhos, esquecimentos e outros, que pareciam banais para a reflexão sobre o homem, passam então a ser analisados como objetos de estudo reveladores daquilo que somos ou nos constituímos. 
efeitos que o público busca no cinema. Para esse movimento, a inutilidade de uma obra de arte tinha mais valor que o seu valor comercial. $\mathrm{O}$ aviltamento do conteúdo foi um dos meios para promover a inutilidade: as poesias, por exemplo, eram 'saladas de palavras', com expressões obscenas. Eles promoveram uma destruição impiedosa da aura em suas criações com o objetivo de provocar a indignação pública. A obra de arte visou atingir o espectador ganhando uma qualidade tátil. Isso contribuiu para fomentar a demanda pelo cinema cuja distração conduz a constantes mudanças de cenários, gerando choques no espectador com imagens que se alteraram com velocidade.

O último capítulo trata da história da cultura de massas. Benjamin afirma que das massas emanam atitudes novas em relação à arte. O número maior de participantes gerou uma nova forma de participação, com mais qualidade. Não se deve enganar com o fato de ter ocorrido criticas severas a essa participação. Georges Duhamel, um dos mais severos críticos do cinema, disse que ele era um passatempo para hilotas, para pessoas sem instrução. Benjamin vai dizer que se trata de uma velha acusação que opõe a distração ao recolhimento. Sustentará que é a obra de arte que penetra nas massas, algo que, na arquitetura, é um exemplo histórico, pois esta última sempre existiu por causa da necessidade de abrigo. Atualmente, devido às grandes mudanças, o aparelho óptico não é suficiente para dar conta da percepção, pois é preciso ultrapassar a contemplação, sendo necessária a recepção tátil. $A$ recepção pela distração é possível, ela é um campo experimental do cinema que vem ao encontro dessa recepção com o seu efeito de choque. A desvalorização do valor de culto ocorre não só ao transformar o público em especialista, mas no fato deste avaliar o filme de forma distraída.

No epílogo, assim como no preâmbulo, a temática política retoma de forma mais explicita. Benjamin sustenta que a crescente proletarização dos homens de sua época e a crescente formação das massas são aspectos de um mesmo processo. O fascismo busca organizar as massas proletárias, mas sem tocar no regime de propriedade. Embora a manifestação dos seus direitos não 
seja permitida, as massas podem se manifestar. $O$ fascismo desemboca em uma estetização da política - esforços que terminam na guerra. Essa última é capaz de oferecer objetivos aos grandes movimentos de massa sem afetar as relações de propriedade, movendo a tecnologia vigente, sustenta Benjamin. Assim, estes fatos podem ser compreendidos politicamente. O filósofo descreve que a apologia fascista não utiliza este argumento, mas ele pode ser defendido. Cita Martinetti como exemplo, que ao escrever uma crítica sobre a guerra colonial na Etiópia, compreende que a oposição à guerra como algo antiestético seria um erro. O filósofo diz, entretanto, que a guerra foi solução encontrada, por causa do bloqueio pelo regime de propriedade, do uso das forças produtivas naturais. Os recursos técnicos, as fontes de energia e outras riquezas, buscam um uso antinatural e a guerra foi a solução encontrada. A guerra imperialista é uma rebelião da técnica que reivindica material humano $o$ que the foi recusado em matérias naturais. A humanidade se tornou um espetáculo para si mesma, sua autoalienação "permite vivenciar a própria destruição como um prazer estético de primeira ordem" (BENJAMIN, 2012, 36).

\section{Reflexões sobre a tecnologia na vida contemporânea}

Após destacar determinados pontos relevantes do texto de Walter Benjamin, entendemos que não se trata de um estudo sobre as questões técnicas e específicas sobre a arte, também não é uma teorização sistemática que tenta reafirmar o lugar da Estética no mundo Moderno, mas o filósofo afirma que desde sempre houve reprodução na arte e isto traz um efeito de transformação sobre a vida humana. Nos modos de reprodução que ocorreram até a Idade Média, as mudanças foram extremamente lentas, por conseguinte, após o surgimento da imprensa e, sobretudo, com a fotografia no século XIX, esta incidência foi cada vez mais presente, para o bem e para o mal. Mas como supracitamos e está evidente no texto, foi o cinema, a técnica de reprodução que trouxe o efeito mais radical. $O$ foco de Benjamin parece ser, sobretudo, 
analisar como a reprodução técnica incide na forma como o ser humano percebe a realidade. Como a relação humana com a tecnologia afeta diretamente a maneira de pensar o mundo e a si mesmo.

São muitos os aspectos a serem analisados neste texto e exatamente por causa da sua riqueza de possibilidades de estudo e reflexão, nos ateremos apenas na questão da perda da aura; do inconsciente óptico e a menção a dimensão política. Quanto à questão da perda da aura, é importante relembrar que esta seria a perda da originalidade, do distanciamento da obra de arte de sua construção original. Benjamin sustenta que desde o momento em que a reprodução da arte se tronou mais efetiva, a perda da aura também ocorreu. Conforme Fátima de Paula, "Benjamin também percebe duas faces nesse processo de dissolução da aura: ele é fator de massificação e imobilismo e está a serviço de uma política de transformação do real" (PAULA, 1994, 116). A perda da aura tem então um aspecto nocivo que é facilitar o comportamento gregário e a falta de atitude diante das coisas que precisam ser enfrentadas na realidade e por outro lado, pode apontar para uma atitude inquieta, que impulsiona a busca de mudanças sociais. Esta questão nos faz pensar nas relações atuais do ser humano com a tecnologia. Marc Jimenez, abordando as reflexões de Benjamin referentes ao declínio da aura, sustenta que estas nos interessam ainda hoje, "porque ultrapassam o momento histórico em que nasceram. De fato, elas acompanham as preocupações contemporâneas sobre o papel ambíguo das mídias em relação à arte e à cultura" (JIMENEZ, 1999, 330). Há uma mediação do corpo com a máquina, o olhar para o mundo está sendo mediado pela tela, basta observarmos a utilização frenética do celular! Embora não se trate necessariamente de uma relação estética, este exemplo nos ajuda a dimensionar, pelo menos minimamente, como a percepção humana está sendo afetada neste embate.

Quanto ao "inconsciente óptico", o fato de Freud, segundo Benjamin, em Sobre a psicopatologia da vida cotidiana, ter passado a valorizar os lapsos de memória, trouxe uma forma diferente de perceber o mundo. Algo que era considerado irrelevante passou a ser objeto de estudo sobre as reações e a 
percepção humana mediante os fenômenos da vida. O nosso objetivo neste texto não é fazer uma análise minuciosa deste efeito na ótica de como o ser humano passou a perceber o mundo, mas de que modo, esta obra de Benjamim nos instiga a atinar para os vários estímulos que recebemos no mundo atual e de que modo eles estão afetando a forma tradicional de enxergarmos a nós mesmos, aos outros e a realidade externa. A presença da televisão, da internet, dos diversos aparelhos científicos e tecnológicos que já fazem parte das vidas atuais, merece uma análise criteriosa sobre os seus efeitos no comportamento, no modo de pensar e até na própria constituição física e mental das pessoas. Cabe a nós, contemporâneos, pensarmos seriamente sobre os seus impactos em uma vida mediada pela tela. Contribui para esclarecer este debate o que sustentou Marshall McLuhan, antes da popularização da internet ou do celular:

[...] toda tecnologia é extensão de nosso corpo humano ou de alguma de suas partes. As roupas são extensões da pele, os móveis, casas, o telefone, o rádio, o cinema, a televisão etc., do nosso sistema nervoso central. Assim, todas as coisas inventadas pelo homem, são extensões de seus sentidos ou de suas faculdades. (MURARO, 1969, 32)

Mesmo que não radicalizemos e compreendamos as novas tecnologias como extensão dos nossos sentidos, parece não ser incoerente considerar em certo grau, ou até em grau ainda mais potente, a tese de McLuhan. O nosso olhar para o mundo não é mais diretivo, a percepção da realidade, quase que necessariamente, perpassa pela intermediação tecnológica.

É comum registrarmos um evento importante não olhando diretamente para ele, mas fazendo isto, tendo como intermediário uma máquina. Ou conversar com alguém via programas de texto e não diretamente utilizando a voz, entre tantos outros exemplos. Não estamos neste momento fazendo nenhum juízo sobre se são corretas ou equivocadas tais atitudes, mas atentando para a necessidade de nos ocuparmos sobre elas, pois para o bem e para o mal, estas estão causando efeitos objetivos e concretos no nosso dia-a- 
dia. Basta atentarmos para números oficiais sobre o aumento do uso das novas tecnologias no Brasil:

\begin{abstract}
O suplemento de Tecnologias da Informação e Comunicação (TIC) da Pesquisa Nacional por Amostra de Domicílios (PNAD) 2014, realizado em convênio com o Ministério das Comunicações, mostrou que, pela primeira vez, o acesso à Internet via telefone celular nos domicílios brasileiros ultrapassou o acesso via microcomputador: de 2013 para 2014, entre os domicílios que acessaram a Internet (inclusive os que utilizaram mais de uma forma de acesso), o percentual dos que o fizeram por microcomputador recuou de $88,4 \%$ para $76,6 \%$, enquanto a proporção dos domicílios que acessavam a Internet por celular saltou de $53,6 \%$ para $80,4 \%{ }^{7}$
\end{abstract}

Apesar da importância destes dados estatísticos, que não são frutos do acaso, mas subjaz aos mesmos uma forma de alimentar o mercado capitalista, interessa ainda questionar como esta intermediação está causando modos de pensar o mundo, modos de perceber o real. Se Freud atentou para uma percepção mais profunda da realidade que extrapolava a visão meramente racional dos fatos, demonstrando que há forças inconscientes que são mais determinantes que a cognição, atualmente, vê-se a presença constante de estímulos externos que invadem o nosso ser a todo o momento e é preciso sopesar até que ponto o nosso consciente-inconsciente está sendo envolvido e movido por estas forças.

As diversificadas visões de mundo que ocorreram na história da humanidade desde a passagem da linguagem oral para a presença da escrita, trouxeram mudanças, críticas, elogios e em todos estes casos, a política esteve presente e de algum modo se aproveitou dos efeitos destes fatos, tanto de forma útil para a coletividade, como de forma nociva e pretendendo a dominação e o controle. $\mathrm{Na}$ atualidade é possível considerar que "a busca sistemática de ganhos de produtividade por meio de várias formas de uso de aparelhos eletrônicos, computadores e redes de comunicação de dados aos poucos foi tomando conta do conjunto das atividades econômicas" (LÉVY,

7 IBGE- Instituto Brasileiro de Geografia e Estatística. Disponível em: http://saladeimprensa.ibge.gov.br/noticias.2014-pela-primeira-vez-celulares-superarammicrocomputadores-acesso-domiciliar-internet. Acesso em 12/07/2016. 
1999, 31), ou seja, independente do momento histórico, as diversas técnicas inventadas pelo homem tiveram intermediação com a política e com a economia, inserido neste contexto, o ensaio de Benjamim em análise, contém uma dimensão política que nos parece bastante direcionada.

Observemos que Benjamim trata do problema político tendo duas bases teóricas principais como pano de fundo. $O$ marxismo, que na sua perspectiva funciona como teoria e prática constituidoras de libertação das consciências, sendo que e a arte funcionou como um dos elementos portadores desta concepção; e o totalitarismo evidenciado pelas suas citações ao fascismo, demonstrando a forma como a arte pode ser utilizada como instrumento de espetacularização da vida e tornar menos dócil o nosso sentimento para com o sofrimento alheio, conforme atesta a citação sobre a Etiópia. Em tempos que assistimos, refugiados apátridas, pessoas desesperadas para fugir da guerra e da fome, e muitas mentes civis e de atores políticos não se mobilizando ou pensando de forma que tal problema seja efetivamente minimizado, enfrentado, criticado; quando negros são mortos por policiais brancos e policiais são hostilizados por negros; crianças indígenas sendo mortas por causa da ideologia consumista; uma violência cada vez mais crescente nas grandes e médias cidades. Tudo isso nos mostra certa espetacularização da vida, um descaso, um não incomodo com o "deixar morrer". Este talvez seja um dos efeitos entorpecentes das novas tecnologias em nossas vidas, parece estar diminuindo ou pelo menos, se evidenciando a incapacidade de pelo menos nos indignarmos. Atesta estas afirmações o comentário de Nery:

A contemporaneidade, marcada pelo espetáculo das guerras globais, testemunha a constatação de Benjamin (1994) quanto à imensa capacidade de produzirmos riquezas e tecnologias $\mathrm{e}$ nossa extrema pobreza espiritual para colocá-las a serviço do conjunto dos seres humanos. (NERY, 2003, 257)

É evidente que não podemos colocar na conta das novas tecnologias a culpa pela indiferença entre os indivíduos. Conforme Muraro, a tecnologia, que é motor do progresso humano e da sua própria transformação é neutra em si, a 
questão é perguntar o que estamos fazendo com ela, por intermédio dela e apesar dela para a existência ser mais humanizada.

As novas tecnologias, por outro lado, contém diversos aspectos positivos; possibilitam que, por intermédio de meios de comunicação, como as redes sociais, que os sujeitos revelem a si mesmos para o mundo, opinem, concordem e discordem com situações e fatos. Inúmeras pessoas tem se organizado para contestar, para revelar as injustiças na administração pública, nos locais de trabalho, na seletividade da imprensa. Ou simplesmente mantendo, via tecnologia, um canal de comunicação com o mundo.

Os fatos supracitados e tantos outros oriundos da relação humana com a tecnologia não deixam de ser um espaço de ação política. Assim como a fotografia e o cinema enveredaram numa enorme transformação nos comportamentos, os inovadores mecanismos de informação como a internet, o celular e outros, trazem também perspectivas positivas e certamente, uma forma nova de percepção da realidade que só no futuro poderemos analisar e definir os seus efeitos com mais precisão. Entretanto, tudo o que está ocorrendo precisa nos incomodar, para que não sejamos meros receptores das novidades tecnológicas que nos são apresentadas, atinando para que sejam minimizados os impactos negativos que elas podem nos causar, entre eles, a diminuição da capacidade de pensar por si próprio. É preciso também, saber absorver os aspectos positivos, e entre tantos outros, podemos apontar o alargamento da relação com a informação, com o conhecimento, com a natureza e, sobretudo, com as pessoas.

\section{Considerações finais}

Antes de terminarmos a nossa análise propriamente, creio que é pertinente citar um fato real, que embora não seja acadêmico ou cientifico, é algo que pode elucidar as reflexões anteriores. Passo a citá-lo: duas 
adolescentes, provavelmente entre treze e quatorze anos, que não conheço, me causaram uma reflexão sobre a influência da tecnologia em nossa percepção. Elas tiravam fotos de uma figura socialmente muito importante, o papa Francisco. Isto ocorreu quando o pontífice esteve no Rio de Janeiro para a última Jornada Mundial da Juventude. Eu, que atualmente não sou uma pessoa religiosa, acompanhava com amigos católicos, com ansiedade e curiosidade, a chegada do primeiro bispo de Roma latino, que a pouquíssimo tempo havia sido eleito. Na hora que o papamóvel passou em nossa frente, ocorreu quase uma "histeria coletiva" e um dilema curioso se estabeleceu entre as jovens, já citadas. Uma delas muito emocionada disse: "eu vi o papa, esta imagem nunca mais sairá de minha retina". A outra por sua vez, um pouco frustrada respondeu: "eu não sei se o vi, eu estava o tempo olhando pela câmera do celular e tirei fotos, filmei, mas eu não sei se o vi"! A outra, ainda movida pela emoção disse um palavrão, com a espontaneidade típica da idade e falou: "é claro que você viu"! E a colega, ainda na dúvida reafirmou: "eu acho que não o vi"! Aquele momento rápido, passado num relance e movido por forte emoção causou um dilema que remete a uma velha e sempre nova questão filosófica: como percebemos o mundo? A jovem que se preocupou prioritariamente em filmar e fotografar o momento, tendo ficado todo o tempo com a tela do celular sobre os olhos, ficou em dúvida se realmente tinha visto o papa. Na prática, é óbvio que ela o viu, mas como não eram os seus olhos, mediados diretamente pelo seu corpo real, isto causou, pelo menos por uns instantes, uma perturbação: mesmo tendo visto, teve o sentimento de não tê-lo feito.

Este fenômeno, que talvez pareça banal, tem, a meu ver, uma questão de fundo extremamente atual: como as novas tecnologias tem influenciado a percepção sobre nós mesmos e sobre os fenômenos que nos circundam? Reflexões a partir das quais podemos retomar Benjamim para quem, "a crise que assim se delineia na reprodução artística pode ser vista como integrante de uma crise própria na percepção" (BENJAMIN, 1989, 39). Esta frase no contexto do contato humano com as novas tecnologias da informação talvez 
pudesse ser refeita - a crise que se delineia pela intermediação dos meios de comunicação no cotidiano humano, pode ser uma crise da percepção.

Tendo como referência o ensaio $A$ obra de arte na era da sua reprodutividade técnica, tencionamos analisar as mídias que todos os dias interagem em nossas vidas, como aquelas advindas da internet e os seus diversos dispositivos; dos celulares cada vez mais modernos, dos vários aparelhos digitais que fazem parte do cotidiano da maior parte das pessoas. É evidente que estas novidades, que tanto nos encantam, trazem sobre nossos corpos, nossa percepção, nossa psique, efeitos. Não é possível dizer que não há nenhum impacto com a entrada de tais aparelhos tecnológicos em nossas vidas, pois afetam o nosso corpo-cognição, a nossa forma de sentir e interpretar o mundo. Os fatos supramencionados são suficientes para gerar algumas perguntas: o que o uso da tecnologia tem feito de nós e o que temos feito desse uso? Somos sujeitos ou assujeitados mediante a sua influência? Conseguimos dominar o seu efeito sobre nossa vontade? Reagimos dialeticamente e equilibradamente à sua presença em nossas vidas? Tudo isto indica que a tecnologia se tornou um problema humano e se é um problema humano é parte necessária da reflexão filosófica.

\section{REFERÊNCIAS}

BENJAMIN, Walter. "A obra de arte na era da sua reprodutibilidade técnica" in: Benjamim e a obra de arte: técnica, imagem, percepção. Tradução de Marijane Lisboa e Vera Ribeiro; org. Tadeu Capistrano. Rio de Janeiro: Contraponto, 2012.

. Charles Baudelaire: um autor lírico no auge da modernidade. São Paulo: Brasiliense, 1989.

FREUD, Sigmund. Obras completas. Madrid, Editorial Biblioteca Nueva, 1973.

IBGE- Instituto Brasileiro de Geografia e Estatística. Disponível em: http://saladeimprensa.ibge.gov.br/noticias.2014- pela-primeira-vez-celularessuperaram-microcomputadores-acesso-domiciliar-internet. Acesso em 12/07/2016. 
JIMENEZ, Marc. O que é estética. Rio Grande do Sul: Ed. Unisinos, 1999.

LÉVY, Pierre. Cibercultura. Trad. Carlos Irineu da Costa. São Paulo: Editora 34, 1999. 264p.

MURARO, Rose Marie. A Automação e o futuro do Homem. Petrópolis: Editora Vozes, 1969. $151 \mathrm{p}$.

NERY, João Elias. "A obra de arte e sua relação com a técnica" in:_Revista Unicsul. São Paulo, v. 8, n. 10, p. 253-259, dez. 2003.

PAULA, Fátima de. "Tensões e ambigüidades em Walter Benjamin: a modernidade em questão" in:__Plural: Revista do Programa de Pós-graduação em Sociologia, São Paulo, v. 1, p. 106-130, 1994.

POLISTCHUK, Ilana; TRINTA, Aluízio. Teorias da comunicação: o pensamento e a prática da comunicação social. Rio de Janeiro: campus, 2003.

SCHOTTKER, Detlev. "Comentários sobre Benjamin e a obra de arte" in: Benjamim e a obra de arte: técnica, imagem, percepção. Tradução de Marijane Lisboa e Vera Ribeiro; org. Tadeu Capistrano. Rio de Janeiro: Contraponto, 2012. 